\title{
GÊNERO EM UM LIVRO DIDÁTICO DO ENSINO MÉDIO: PROBLEMATIZANDO REPRESENTAÇÕES
}

\author{
GENDER IN A HIGH SCHOOL TEXTBOOK: PROBLEMATIZING REPRESENTATIONS
}

Katia Costa Santos *

Instituto Federal de Minas Gerais (*)

E-mail: katia.santos@ifmg.edu.br

\section{Resumo}

O artigo apresenta resultados parciais de uma pesquisa que analisou um livro didático como instrumental de uma pedagogia da sexualidade no contexto escolar, que formata e legitima saberes, identidades de gênero, diferenças e desigualdades. Em especial, a pesquisa problematizou categorias de representação de gênero em um livro didático de matemática, utilizado por estudantes do Ensino Médio de uma instituição de ensino em Minas Gerais, e constatou como tais representações ainda legitimam posições hierarquizantes de sujeito, (re)produzem os estereótipos de gênero e diversidade presentes na educação e em nossa sociedade. Os resultados apontaram, mais uma vez, a urgência de investimentos em uma micropolítica de desestabilização de nossas escolhas, ações e representações no/do espaço escolar de forma a reduzir os processos discriminatórios a que estão sujeitas as representações do gênero feminino nas mais diversas instâncias desse espaço.

Palavras-chave: desigualdade, gênero, livro didático, representação

\begin{abstract}
This article presents partial results of a research that analyzed a textbook as instrumental of a pedagogy of sexuality in the school context that formats and legitimizes knowledge, gender identities, differences and inequalities. In particular, the research problematized categories of gender representation in a math textbook, used by High School students of an educational institution in Minas Gerais, and verified how such representations still legitimize hierarchized positions of subject, (re) produce the gender and diversity ideology present in education and society. The results indicate the urgency of investments in destabilization micropolitics of our choices, actions and representations in/of the school context in order to reduce the discriminatory processes that the female gender representations are submitted to in the different scopes of that space.
\end{abstract}

Keywords: inequality, gender, textbook, representation 


\section{INTRODUÇÃO}

As relações de gênero são profundamente marcadas por construções histórico-sociais. Tais relações têm sua manutenção garantida por discursos e práticas pedagógicas escolares, que têm contribuído para a reprodução de desigualdades entre homens e mulheres em nossa sociedade. A escola é um espaço privilegiado de produção de tais construções. Espaço esse que reproduz e reafirma as relações sociais e sexuais produzidas por meio das relações assimétricas de poder. Com efeito, como aponta Guacira Louro (2001), é importante compreender "que a sexualidade não é apenas uma questão pessoal, mas é social e política" e ainda, ela "é aprendida, ou melhor, é constituída, ao longo de toda a vida, de muitos modos por todos os sujeitos".

O espaço escolar é, portanto, delineado por um conjunto de saberes e significados, corporificados em seu currículo, que projeta as prováveis identidades, suas construções, e as relações de alteridade com o Outro. Em especial, essa construção é delimitada por uma cultura recortada historicamente, que restringe, dentro de seus ideais reguladores, quais serão essas prováveis identidades.

A escola, então, aparamentada com todas as suas práticas heterossexistas ${ }^{1}$ reitera saberes e lugares possíveis e cabíveis às meninas e aos meninos, essencializando as identidades, pois tem dificuldade em compreender como essa naturalização de comportamentos sociais e sexuais é, de fato, construída e reforçada por discursos e práticas pedagógicas. Assim, a escolha de planos e conteúdos de currículos, de livros didáticos, as estratégias em sala de aula, as prováveis aceitações de comportamentos tidos como "normais", dentre outros, são instrumentais de formatação de saberes e identidades que, de forma sutil e sorrateira, como nos diz McLaren (1997:11), serve para "reproduzir ideologias (...) que caracterizam as sociedades dominantes".

Diante desse quadro, este artigo apresenta os resultados parciais de uma pesquisa que discutiu o livro didático como instrumental de promoção de uma pedagogia da sexualidade no contexto escolar. Em especial, o estudo descreve e problematiza categorias de representação de gênero

\footnotetext{
${ }^{1}$ Expressão entendida neste artigo como a atitude de preconceito, discriminação ou ódio contra toda sexualidade não-heterossexual.
} 
presentes (em texto e imagem) em um livro didático de matemática, utilizado por estudantes do Ensino Médio, de uma instituição de ensino em Minas Gerais.

Tal análise está centrada em apropriações teóricas da Pedagogia Crítica, Estudos Culturais, Pósestruturalismo e Teoria de Gênero, e se justifica diante da necessidade de multiplicação de tais saberes junto a docentes, sensibilizando-os sobre a urgência de uma postura crítica para a sua prática pedagógica.

Muitas vezes, supomos que por nos parecer tão óbvia a desigualdade nas representações do gênero masculino e feminino presentes nos livros, nos recursos e práticas pedagógicas dentro e fora da escola, não precisamos mais insistir nessa denúncia, mas a realidade de nossas escolas brasileiras hoje, mesmo nos grandes centros, nos constrange a uma necessidade premente de caminhar em direção oposta. Há uma demanda real que nos compele a desestabilizar padrões de construção do conhecimento, desconstruindo tradições e verdades, com vistas a uma compreensão mais ampla dos processos de construção social dos significados simbólicos a que nos expomos e expomos nossos estudantes diariamente.

Tal postura reveste-se, ainda, de um desafio aos "papeis que as escolas representam em nossa vida política e cultural" (McLaren, 1997). Esses papéis, como sabemos, estão sempre unindo saber e poder, e fazem da escolarização um espaço de conformidade e legitimação de verdades. Nosso desafio é, portanto, desmistificar saberes, refletir com e na escola sobre como ela sustenta saberes, conceitos, comportamentos sobre a sexualidade que, infelizmente, reproduzem os espaços de desigualdade por ela/nela constituídos.

\section{PRESSUPOSTOS TEÓRICOS}

As identidades e diferenças são construídas, tratadas e ocultadas no contexto social, e, em especial, no escolar. A escola é um campo conflituoso de produção/reprodução cultural e social e o currículo ocupa um papel central nesse processo. Através dele a cultura/ideologia dominante se impõe, identidades se constituem, relações sociais e de poder se expressam. 
Nesse contexto, a Pedagogia Crítica tem caminhado, de certa forma, como nos afirma SANTOS (2002), "na contramão das políticas e práticas educacionais que têm informado o sistema educacional brasileiro", pois deseja compreender a relação entre conhecimento e poder, já que o conhecimento não é neutro. Busca refletir sobre como os sistemas de inteligibilidade são construídos, como a ideologia hegemônica se reproduz, como as práticas culturais representam e organizam o poder, como o currículo constitui, formata e legitima as identidades e diferenças, como o livro didático, com seu selo de autoridade, tem sido um instrumental poderoso de tais objetivos.

A contribuição do pós-estruturalismo foi fundamental para essa nova forma de conceituar e problematizar o poder, em sua relação com o saber. Como nos diz SILVA (1999), Foucault transformou a noção de poder, sua direcionalidade, concebendo-o como relacional, móvel, fluido, a origem do processo pelo qual nos tornamos o sujeito que somos. Para ele, poder e saber são interdependentes: “... não existe saber que não seja a expressão de uma vontade de poder; assim como não existe poder que não utilize o saber".

Os instrumentos discursivos e institucionais são construtores de nossas identidades. Em especial, a forma como as proposições discursivas são apresentadas no livro didático e tratadas no espaço escolar são catalizadoras dessas relações. Perceber as estratégias de poder que se manifestam por meio de tais proposições é o primeiro passo a caminho de ações que reivindiquem visibilidade e menos desigualdade para as representações do gênero feminino.

Derrida (apud LEAL, 20009), ao ampliar o conceito de diferença do estruturalismo, por uma via diferente de Foucault, enfatiza a questão do significado, do conhecimento como um construto cultural, socialmente instituído.

Interessa-nos o destaque concedido por ele ao processo pelo qual algo é considerado verdade, ampliando questionamentos e discussões críticas a respeito de como "verdades" são construídas, tradições inventadas, memórias e histórias esquecidas. E, ainda, sua busca por desconstruir binarismos/dicotomias (tão típicos de nosso currículo e prática escolar). Na análise do livro didático objeto de nossa pesquisa fica evidente a invisibilidade de outras identidades sexuais e, por conseguinte, a restrição de nossa análise à problematização das representações do masculino e 
feminino, as quais, ainda que limitadas a desse binarismo, discutem a discriminação nesse escopo das identidades sexuais.

A preocupação com as variadas formas pelas quais o poder se apresenta e opera no âmbito social tem recebido uma densa contribuição dos Estudos Culturais, em sua revisão da concepção de cultura como um campo de construção social que define a forma como as pessoas e os grupos devem ser.

Tal espaço é notadamente permeado por relações de poder que engendram as relações sociais em luta por imposição de significados. Essa visão nos ajuda a compreender a dinâmica de constituição do conhecimento escolar: os saberes representados por meio da escolha dos livros didáticos adotados, das práticas pedagógicas, dos planos de ensino elaborados: uma construção social, que não pode ser compreendida em separado das relações de poder que definem a presença ou ausência de um saber no currículo escolar.

Diante dessa constatação, os Estudos Culturais fazem convergir esse instrumental teórico, a fim de estabelecer uma política da diferença que aponte para uma alternativa ao padrão cultural colonial presente em nossos currículos, ainda tão moldados por tal herança. Essa alternativa percebe na ação agenciadora uma forma de intervir no processo discursivo de construção de sentidos e representações do mundo (JORDÃO apud OLIVEIRA, 2012). Portanto, é fundamental que nossos educadores sejam expostos ao conhecimento dos processos geradores de tais construções durante sua formação docente inicial e continuada, em cursos de qualificação, em eventos e produções acadêmico-científicas, na prática docente com os seus pares, a fim de intervirem nos currículos, nas práticas pedagógicas, nas concepções discriminatórias sobre gênero construídas nas representações presentes nos livros didáticos.

As diferenças marcadas por determinantes de gênero e os processos de desigualdade que a acompanham encontram em Scott (1995) apropriações de alguns conceitos das teorias pós-críticas para propor um novo paradigma teórico em que o gênero é percebido como um artefato de construção social e histórica, e instrumental de expressão de desigualdade de poder. A autora propõe a necessária articulação do sujeito individual, no caso, as mulheres, com a organização 
social mais ampla, objetivando incluir a noção do político, das instituições, em especial a escola, da organização social, para poder examinar como são construídas as identidades subjetivas de gênero.

Apropriamo-nos desse paradigma para demonstrar, por um lado, como as representações do masculino e feminino no capítulo analisado atuam como elementos discursivos, ensinando e reproduzindo as representações que emolduram, via invisibilização/discriminação, a construção das identidades sexuais, contribuindo, assim, para manter a desigualdade entre os gêneros. Por outro, como tais processos ainda se mostram silenciados nos currículos, quer nos materiais didáticos, como pode ser observado no livro didático analisado, quer nos currículos de formação docente, ou até mesmo como eixo integrante de uma política pública preocupada com a formação de sujeitos que compreendam e respeitem a diferença.

O respeito à diferença, ao supor a aceitação daquele/a que não the é semelhante, não exige conformidade com os valores, crenças, atitudes ou comportamentos que marcam tal diferença no Outro. Vejamos o exemplo da diferença religiosa. Um sujeito não cristão ao respeitar um cristão não o faz porque concorda com os seus valores e doutrinas religiosas, mas assim se coloca por compreender o direito inalienável que cada ser humano tem de pensar, sentir e agir segundo seus próprios padrões. De modo semelhante, o respeito a um sujeito que conviva com uma obesidade mórbida não se pauta em conformidade com o seu estilo de vida, mas na percepção de compreensão da situação física em que se encontra. E ainda, o respeito entre sujeitos que partilhem de identidades sexuais distintas não está centrado em um vínculo de empatia de valores, mas de um vínculo que eu denomino de empatia de natureza.

Portanto, o respeito à diferença pode ser melhor compreendido quando baseia-se em uma percepção anterior de que o Outro possui a mesma natureza que possuímos (Geertz, 1997). Assim, ao ver-nos no Outro sob essa ótica, conseguimos compreender que o Outro poderia ser eu mesma, você mesmo. Essa é a motivação e o desafio para que o respeito torne-se mais que uma tolerância hipócrita para avançarmos nas lutas contra a desigualdade e segregação. 


\section{PERCURSO METODOLÓGICO}

O objeto de análise dessa pesquisa foi o capítulo 10: Matemática financeira do seguinte livro didático:

DANTE, Luiz Roberto. Matemática: contexto e aplicações. São Paulo: Ed. Ática, 2011.

A escolha do livro levou em consideração o fato de ser esse o livro adotado por docentes do Ensino Médio, na instituição onde o Grupo de Pesquisa em Educação Matemática e Relações de Gênero atuava. A opção pelo capítulo 10 foi pautada em algumas considerações vinculadas ao tema e possibilidade de presença das categorias de análise selecionadas.

Assim, ao considerarmos o recorte que faríamos do livro a ser analisado, verificamos que o tema do capítulo 10 (matemática financeira) foi o que se mostrou mais apropriado aos nossos objetivos, pois trata de conceitos matemáticos aplicados à análise de dados financeiros em geral, ou seja, uma área especialmente prática, aplicada em situações particulares e objetivas, já que a simples decisão de comprar um bem a prazo ou à vista, por exemplo, envolve conhecimentos financeiros. Portanto, implicaria em uma possível diversidade de contextos do mundo público e privado, bem como de sujeitos envolvidos.

Nosso objetivo de análise foi descrever e problematizar referenciais de gênero contidos no capítulo a partir do mapeamento de algumas categorias de análise selecionadas para esse fim.

Para fins de operacionalização dessa análise, a estrutura do capítulo foi segmentada em fragmentos discursivos teóricos $(T)$, exemplos $(E)$, exercícios propostos e atividades adicionais (EPAA). Verificamos como a contextualização ocorre em cada um desses segmentos e quantificamos a contextualização segundo três critérios: segmentos descontextualizados, segmentos em contexto situacional e segmentos em contexto específico. Após, analisamos todos os segmentos apresentados em contexto específico. A tabela 1 mostra o quantitativo dos segmentos analisados no capítulo, tendo em vista o critério de contextualização.

\section{TABELA 1}

QUADRO GERAL DOS SEGMENTOS ANALISADOS NO CAPÍTULO 


\begin{tabular}{|c|c|c|c|c|}
\hline \multirow{2}{*}{ Tipo de segmento } & \multicolumn{3}{|c|}{ Critério de contextualização } & \multirow{2}{*}{ Total } \\
\cline { 2 - 5 } & $\begin{array}{c}\text { descontex- } \\
\text { tualizado }\end{array}$ & $\begin{array}{c}\text { contexto } \\
\text { situacional }\end{array}$ & $\begin{array}{c}\text { contexto } \\
\text { específico }\end{array}$ & \\
\hline teórico & 10 & 9 & $4(* 9 \mathrm{rl})$ & 23 \\
\hline exemplo & 8 & 11 & $8\left(^{*} 9 \mathrm{rl}\right)$ & 27 \\
\hline $\begin{array}{c}\text { exercício proposto e } \\
\text { atividade adicional }\end{array}$ & 9 & 45 & $38(* 42 \mathrm{rl})$ & 92 \\
\hline TOTAL & 27 & 65 & $50(* 60 \mathrm{rl})$ & 142 \\
\hline
\end{tabular}

*A ocorrência de mais de um referencial lexical (rl) por segmento gerou um quantitativo maior de referenciais lexicais se comparados ao de segmentos analisados.

A análise dos segmentos em contexto específico (tabela 2) considerou as seguintes categorias analíticas: os referenciais lexicais de representação de gênero, a inserção dos temas tratados no mundo público ou privado e os processos discursivos de empoderamento contidos nos fragmentos.

TABELA 2

QUADRO GERAL DAS CATEGORIAS ANALISADAS EM CONTEXTO ESPECÍFICO NO CAPÍTULO

\begin{tabular}{|c|c|c|c|c|c|c|}
\hline \multirow{3}{*}{ Tipo de segmento } & \multicolumn{5}{|c|}{ Categorias de de análise } & \multirow{3}{*}{ TOTAL } \\
\hline & \multicolumn{3}{|c|}{ Referenciais lexicais } & \multirow{2}{*}{$\begin{array}{c}\text { Mundo } \\
\text { público/privado }\end{array}$} & \multirow[t]{2}{*}{ empoderamento } & \\
\hline & $M$ & $\mathrm{~F}$ & 1 & & & \\
\hline$T$ & 5 & 0 & 4 & & & 9 \\
\hline$E$ & 4 & 3 & 2 & & & 9 \\
\hline EPAA & 23 & 6 & 13 & & & 42 \\
\hline TOTAL & 32 & 9 & 19 & & & 60 \\
\hline
\end{tabular}




\subsection{Contextualização do conteúdo}

A relevância do contexto em situações de aprendizagem é apoiada pela abordagem construtivista, que compreende o contexto como extremamente importante para que haja uma aprendizagem significativa. No centro do pensamento construtivista, o contexto se expressa por meio da interação do indivíduo com suas atividades, com os outros indivíduos e com o espaço. Nos fragmentos analisados, supõe-se a presença de sujeitos e elementos circunstanciais como necessários à construção de tal processo de aprendizagem.

Sanchis e Mahfoud (2007), ao analisarem os processos de interação entre o sujeito e o conhecimento no construtivismo de Piaget, ratificam a proposição de que todo e qualquer desenvolvimento cognitivo só se torna efetivo se for baseado em uma interação muito forte entre o sujeito e o objeto. Para os autores “... é imprescindível que se compreenda que sem uma atitude do objeto que perturbe as estruturas do sujeito, este não tentará acomodar-se à situação, criando uma futura assimilação do objeto, dando origem às sucessivas adaptações do sujeito ao meio, com o constante desenvolvimento de seu cognitivismo", por meio da aprendizagem.

No âmbito discursivo, em proposições marcadas pela ausência de contexto ou contexto situacional não existe uma situação mínima apresentada no enunciado que delimite o sentido da enunciação (Ducrot, 1987). Como consequência, tais proposições oferecem um nível de transposição mais remota pelo/a estudante para situações do cotidiano, já que as proposições têm elementos restritos de especificação, que comprometem o processo de construção de um conhecimento novo a partir de tal atividade.

Consideramos em contexto situacional as proposições que têm como objeto de análise um fato (índice de peças defeituosas - ex. proposto 1, p. 337; uma quantia em reais - ex. proposto 6, p. 340), apresentado ou não em um contexto hipotético (uma indústria de rolamentos, no mês de abril/junho - ex. proposto 1, p. 337) sem o envolvimento de sujeitos e circunstâncias. Tal formatação tem como efeito a produção de um contexto hipotético muito distante de uma situação apresentada com especificações de categorias de sujeitos, geográficas, históricas, sociais, e tantas outras. Portanto, entendemos que os fragmentos descontextualizados ou apresentados em contexto situacional comprometem o processo ensino-aprendizagem de estudantes. 
Compreendemos, ainda, como em contexto específico as proposições que, além do objeto de análise, suponham a presença de sujeito/s e elementos circunstanciais mínimos que possibilitem uma interação entre sujeito e objeto, com vistas à construção do conhecimento. Essas proposições constituíram nosso objeto de análise, tendo em vista a hipótese de descrição e problematização das categorias de análise dos referenciais de gênero nesses segmentos.

\subsection{Referenciais lexicais de representação de gênero}

Alocamos os referenciais lexicais vinculados aos sujeitos envolvidos nos segmentos analisados em três critérios: referenciais para o masculino, para o feminino e para o que denominamos de "indeterminação de gênero". Nesse último critério, os seguintes recursos linguísticos foram considerados:

\section{QUADRO 1}

\section{RECURSOS LINGUÍSTICOS DE INDETERMINAÇÃO DE GÊNERO}

\begin{tabular}{|l|l|l|}
\hline \multirow{2}{*}{ Léxico } & Uma pessoa, a população & Substantivos sobrecomuns \\
\cline { 2 - 3 } & Cliente, motorista & $\begin{array}{l}\text { Substantivos comuns de } \\
\text { dois gêneros, quando } \\
\text { destituídos } \\
\text { determinantes }\end{array}$ \\
\hline \multicolumn{2}{|c|}{ *Plural de generalização } & torcedores, povos, banqueiros \\
\hline $\begin{array}{l}\text { * A língua portuguesa determina que o plural dos substantivos, quando abrange tanto indivíduos do gênero } \\
\text { feminino quanto do gênero masculino, é feito com base no masculino: "vinte professoras" e "dez } \\
\text { professores", juntos, são "trinta professores"; uma sala de aula com trinta e nove alunas e um único aluno } \\
\text { terá no total "quarenta alunos". Essa regra inclui tanto os substantivos de } 2 \text { gêneros, quanto aqueles que têm } \\
\text { formas específicas para masculino/feminino. }\end{array}$
\end{tabular}

\subsection{Mundo público e privado}

A análise dessa dicotomia demonstra como nossa sociedade tem definido papéis vinculados às representações do que denominamos masculino e feminino e esses espaços dicotomizados. 
Assim, observamos a nítida distinção que fazemos para a vinculação do masculino ao mundo público: o das relações diversas que se estabelecem para além da família, da casa do sujeito analisado, tomando os rumos da comunidade mais ampla e da sociedade em geral; e o mundo privado, que se apresenta em uma vinculação estreita com o feminino: um espaço de pertencimento ao ambiente familiar, à casa, ao que é de uso pessoal. Analisamos, a partir dessa perspectiva, o contexto de produção dos discursos envolvidos nos fragmentos analisados, buscando definir, quando possível, não só o lugar de ação do/s sujeito/s envolvido/s, como também a relação de pertencimento entre o/s sujeito/s e o objeto de análise.

\subsection{Empoderamento}

Apropriamo-nos da concepção de Gohn (2004) sobre empoderamento para descrição dessa categoria de análise. Curioso notar a vinculação que a autora faz desse conceito ao que ela denomina "processos que tenham a capacidade de gerar processos". Para ela, trata-se de um processo de mobilizações e práticas que objetivam promover e impulsionar um grupo ou comunidade "a ser protagonista de sua própria história", ou seja, a um processo de ruptura com o estado de tutela e impotência, apropriando-se, como nos diz Herriger (apud Kleba e Wendausen, 2009): “... de habilidades de participação democrática e de poder político de decisão”.

O empoderamento envolve, portanto, um processo de reflexão, produção de narrativas e implementação de políticas eficazes voltadas à conquista do que denominaríamos "autonomias possíveis" para sujeitos em seus diversos espaços de atuação. O livro didático, como diversos outros recursos pedagógicos, é um instrumental de produção de narrativas, que se mostram construtoras da visão de mundo, dos comportamentos, dos relacionamentos, valores, ideologias, enfim, das identidades dos sujeitos que dele se utiliza.

Selecionamos apenas um aspecto do processo discursivo presente nos fragmentos teóricos, e nos enunciados dos exemplos, exercícios propostos e atividades adicionais como critério de análise da referida categoria: a relação sujeito/s-objeto/s, por meio de a análise textual-discursiva dos verbos presentes nos segmentos. 
Os verbos, conforme tipologia textual defendida por TRAVAGLIA (1991) expressam situações (processos, eventos, estados, ações, fatos, fenômenos, etc.). Em especial, os verbos analisados representam situações de ação, que se caracterizam por ter um agente que realiza a situação por seu empenho próprio, representado por algo como " $x$ faz $y$ ". Analisamos a vinculação entre as situações de ação e suas representações como narrativas, seus significados e força discursiva como processo de empoderamento, silenciamento e desigualdade. Buscamos constatar a estreita vinculação entre processos de empoderamento (ou ausência dele) nas relações sociais e os referenciais de gêneros a ele relacionados. Ou seja, há uma manifestação expressa de poder vinculada às representações do masculino e a manifestação de submissão, ausência de poder, relacionada ao feminino. Tais manifestações podem ser observadas nas intenções expressas por meio de os verbos presentes nos segmentos analisados. 


\section{ANÁLISE E RESULTADOS}

A análise dos dados foi feita em conformidade com as categorias acima descritas e as segmentações de fragmentos teóricos, exemplos, exercícios propostos e atividades adicionais (tabela1).

\subsection{Fragmentos teóricos}

Consideramos como textos teóricos aqueles em que houve apresentação e explicação de conteúdo novo, acompanhados ou não de exemplos. Foram analisados 23 fragmentos de textos teóricos, dos quais 10 foram apresentados sem contexto, 9 apresentados em contexto situacional e 4 em contexto específico (tabela 3).

\section{TABELA 3}

ANÁLISE DOS FRAGMENTOS TEÓRICOS EM CONTEXTO ESPECÍFICO

\begin{tabular}{|c|c|c|c|c|c|c|c|}
\hline$* S$ & $M$ & $\mathrm{~F}$ & 1 & $E$ & $\begin{array}{l}\text { PUX } \\
\text { PR }\end{array}$ & 0 & $P$ \\
\hline 1 & & & Os povos & $\begin{array}{c}\text { Começaram a trocar o } \\
\text { excedente }\end{array}$ & pu & mercadoria & 336 \\
\hline 1 & ourives & & & Negociava & pu & Ouro e prata & 336 \\
\hline 1 & pessoa & & & Negociava & pu & Ouro e prata & 336 \\
\hline 1 & & & $\begin{array}{c}\text { Os } \\
\text { proprietários }\end{array}$ & $\begin{array}{c}\text { Ficavam com recibo... para } \\
\text { efetuar pagamentos }\end{array}$ & $\mathrm{pu}$ & valores & 336 \\
\hline 1 & $\begin{array}{c}\text { Banqueiro/ } \\
\text { escritórios } \\
\text { de } \\
\text { banqueiros }\end{array}$ & & & Cobrava altas taxas & pu & dinheiro & 336 \\
\hline ST & 3 & 0 & 2 & & & & \\
\hline 2 & & & Uma pessoa & Vai fazer uma compra & $\mathrm{pu}$ & $x$ & 338 \\
\hline 3 & & & Oito pessoas & $x$ & $\mathrm{pu}$ & $x$ & $340-6$ \\
\hline
\end{tabular}




\begin{tabular}{|c|c|c|c|c|c|c|c|}
\hline 4 & \begin{tabular}{|ll} 
Uma & \\
pessoa... & a \\
pessoa... & o \\
cliente &
\end{tabular} & & & Terá em sua conta & pu & dinheiro & 346 \\
\hline 5 & $\begin{array}{l}\text { Meu } \\
\text { dinheiro } \\
\text { rende }\end{array}$ & & & $\begin{array}{l}\text { É mais vantajoso pagar agora } \\
\text { ou...? }\end{array}$ & pu & quantia & 353 \\
\hline$T$ & 5 & 0 & 4 & 8 & 9 & & \\
\hline
\end{tabular}

*LEGENDA

\begin{tabular}{|c|c|c|c|}
\hline S & segmento & PU X PR & público $\times$ privado \\
\hline M & masculino & P & página \\
\hline F & feminino & O & objeto \\
\hline I & indeterminação de gênero & ST & subtotal \\
\hline E & empoderamento & T & total \\
\hline
\end{tabular}

Os 4 fragmentos analisados apresentam 9 referências de sujeito. Há uma predominância de referenciais do gênero masculino ( 5 ocorrências), nenhum marcador lexical para o gênero feminino e 4 referenciais para a indeterminação de gênero. As representações de empoderamento foram observadas nas formas verbais (comprar, aplicar, pagar, efetuar pagamento, trocar) de fragmentos em que as representações de gênero eram masculinas. Portanto, houve uma relação entre empoderamento e gênero masculino. Em especial, os 4 fragmentos reportam-se ao mundo público.

Além dos fragmentos em texto, o autor fez uso de duas imagens (figuras 1 e 2), com objetivos diferenciados, ao longo de todo o capítulo. No primeiro caso (fig. 1), a imagem foi usada para corroborar a descrição de uma instituição financeira bancária. Para isso, utilizou-se de uma imagem do Chemical Bank, em Nova York, 1885. A ilustração apresenta quatro possíveis funcionários no interior do Banco e um cliente, todos representando o gênero masculino. Interessante notar que a apresentação do capítulo é feita no fragmento teórico no. 1 e acompanhada da imagem acima descrita ratifica a supremacia do gênero masculino no contexto do tema do capítulo analisado. 
No segundo caso, em um fragmento teórico apresentado em contexto situacional, o autor reproduz uma imagem do Banco Central do Brasil em Brasília, DF. Tal como o texto, que se abstém de um contato maior com o leitor via ausência de sujeitos que remetam a uma identificação e compreensão mais concreta dos significados abordados, a imagem do Banco Central é tão somente a externa do prédio, que, por si só, é observada como evasiva e ratifica as limitações do texto no que tange ao processo de aprendizagem.

FIGURA 1 - Chemical Bank, NY, 1885

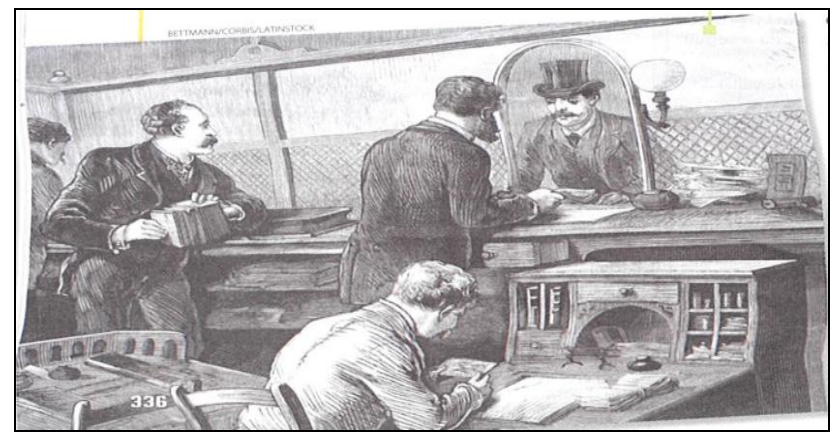

Fonte: DANTE, LR. Matemática: contexto e aplicações, p. 336, 2010.

FIGURA 2 - Banco Central do Brasil, DF

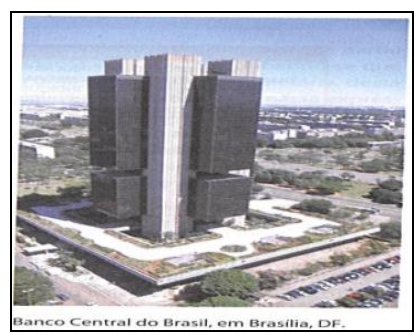

Fonte: DANTE, LR. Matemática: contexto e aplicações, p. 357, 2010.

O quantitativo de referenciais de sujeito em fragmentos teóricos pode ser visualizado no gráfico de descrição percentual a seguir.

\section{GRÁFICO 1}

\section{REFERENCIAIS DE SUJEITO EM FRAGMENTOS TEÓRICOS}




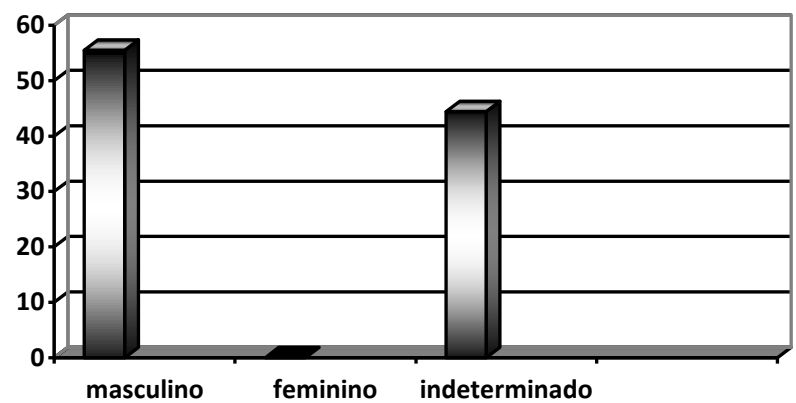

O gráfico demonstra que $55,5 \%$ dos referenciais de sujeito presentes nos fragmentos teóricos são para o gênero masculino, $0 \%$ para o gênero feminino e 44,4\% expressam indeterminação de gênero. Vale notar que em todos os segmentos marcados por indeterminação de gênero observamos marcas discursivas de empoderamento e um contexto específico do mundo público, ou seja, talvez tenhamos muito mais uma busca por aparente neutralidade no âmbito linguístico, permeada por um valor discursivo fortemente masculino.

\subsection{Exemplos}

O capítulo fez uso de 27 exemplos como recurso de transposição didática dos conceitos apresentados e o contexto imediato, após a apresentação do texto teórico. Desse total, 8 exemplos são descontextualizados, 11 em contexto situacional e 8 em contexto específico. 0 quadro a seguir (tabela 4) descreve a análise dos 8 exemplos apresentados em contexto específico:

TABELA 4

ANÁLISE DOS EXEMPLOS EM CONTEXTO ESPECÍFICO

\begin{tabular}{|c|c|c|c|c|c|c|c|}
\hline$* S$ & $M$ & $\mathrm{~F}$ & I & $E$ & $\begin{array}{c}\text { PUX } \\
\text { PR }\end{array}$ & 0 & $P$ \\
\hline 1 & $\begin{array}{l}\text { Um } \\
\text { trabalhador }\end{array}$ & & & $\begin{array}{l}\text { Recebeu } \\
\text { aumento }\end{array}$ & pu & salário & $345-2$ \\
\hline 2 & & Laura & & Gastou X & $\mathrm{pr}$ & $\begin{array}{l}1 \text { bicicleta, } 1 \\
\text { ap. som, } 1 \\
\text { estante }\end{array}$ & $345-3$ \\
\hline 3 & & & Uma & investiu & $\mathrm{pu}$ & investimento & $349-6$ \\
\hline
\end{tabular}




\begin{tabular}{|c|c|c|c|c|c|c|c|}
\hline & & & pessoa & & & & \\
\hline 4 & João & & & investiu & $\mathrm{pu}$ & carro & $350-5$ \\
\hline 5 & & & $\begin{array}{l}\text { Uma } \\
\text { pessoa }\end{array}$ & pagou & $\mathrm{pu}$ & compra & $350-6$ \\
\hline 6 & & Rosângela & & $\begin{array}{l}\text { Tomou } \\
\text { emprestado }\end{array}$ & $\mathrm{pu}$ & dívida & 354-1 \\
\hline 7 & & Hélen & & $\begin{array}{l}\text { Tem } 2 \text { opções } \\
\text { para } \\
\text { pagamento }\end{array}$ & $\mathrm{pr}$ & TV & 354-2 \\
\hline 8 & $\begin{array}{l}\text { Um } \\
\text { vendedor }\end{array}$ & & & $\begin{array}{l}\text { Oferece } \\
\text { alternativas } \\
\text { de } \\
\text { pagamento }\end{array}$ & $\mathrm{pu}$ & $\begin{array}{l}\text { Conjunto de } \\
\text { sofá } \\
\text { Contexto: } \\
\text { investimento }\end{array}$ & $355-5$ \\
\hline 8 & O cliente & & & $\begin{array}{l}\text { Melhor } \\
\text { alternativa } \\
\text { para o custo } \\
\text { de } \\
\text { oportunidade }\end{array}$ & $\mathrm{pu}$ & $\begin{array}{l}\text { Conjunto de } \\
\text { sofá } \\
\text { Contexto: } \\
\text { investimento }\end{array}$ & $355-5$ \\
\hline$T$ & 4 & 3 & 2 & & & & \\
\hline
\end{tabular}

\section{*LEGENDA}

\begin{tabular}{|c|c|c|c|}
\hline S & segmento & PU X PR & público x privado \\
\hline M & masculino & P & página \\
\hline F & feminino & O & objeto \\
\hline I & indeterminação de gênero & T & total \\
\hline E & empoderamento & & \\
\hline
\end{tabular}

Os 8 exemplos analisados apresentam 9 referências de sujeito. Os resultados demonstram a predominância do gênero masculino, com 4 ocorrências; 3 marcadores lexicais para o gênero feminino e 2 para indeterminação do gênero. Interessante notar a ocorrência de 2 marcadores lexicais de gênero masculino envolvendo a aquisição de um item aparentemente vinculado ao 
mundo privado (1 conjunto de sofá). Entretanto, um olhar mais atento pode perceber que a centralidade do problema não está vinculada à melhor forma de pagamento do produto, mas a uma melhor alternativa de investimento. Assim, temos um contexto típico do mundo público.

Além disso, a análise das relações de empoderamento ratifica a situação de uso do poder/empoderamento para o gênero masculino e de submissão ou ausência de empoderamento para o gênero feminino, ao observarmos as ações envolvidas por meio das expressões verbais analisadas.

O quantitativo de referenciais de sujeito em exemplos pode ser visualizado no gráfico de descrição percentual a seguir.

\section{GRÁFICO 2}

\section{REFERENCIAIS DE SUJEITO EM EXEMPLOS}

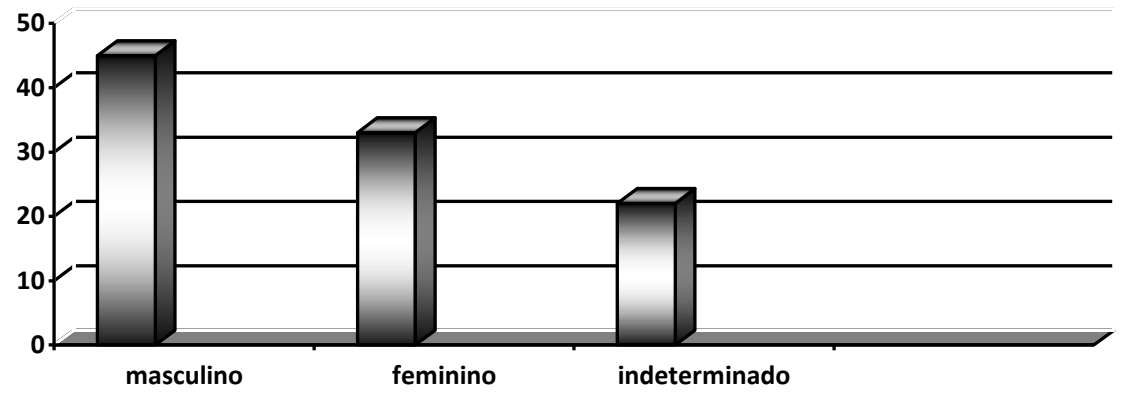

O gráfico apresenta um quadro diferenciado para a presença de referenciais femininos, com um percentual de 33\%. Mas a supremacia do gênero masculino ainda permanece, com percentual de $45 \%$ do total de exemplos analisados. A indeterminação de gênero representa $22 \%$ dos exemplos.

Uma análise dos processos discursivos de empoderamento demonstra que nos 3 exemplos com referenciais de sujeito feminino (tabela 4) as ações envolvidas são: Laura gastou dinheiro para comprar uma bicicleta, um aparelho de som e uma estante; Rosângela tomou dinheiro emprestado para pagamento de uma dívida e Hélen teve 2 opções para pagamento de uma TV.

Nos três casos, as ações envolvem situações de aquisição de bens de uso pessoal ou familiar, ou situação de endividamento e gasto de dinheiro. Nenhuma dessas situações foi encontrada no 
capítulo para referenciais de sujeito masculino. Até mesmo o segmento 8 , que aparentemente nos reportaria ao mundo privado por tratar-se de a compra de um conjunto de sofá, não procede, pois a proposição final do enunciado refere-se a um investimento, o que novamente nos reporta ao mundo público e a processos discursivos de empoderamento.

\subsection{Exercícios propostos e atividades adicionais}

Foram analisados 75 exercícios propostos e 17 atividades adicionais, perfazendo um total de 92 exercícios analisados. Deste total, 9 foram apresentados de forma descontextualizada, 45 em contexto situacional e 38 em contexto específico, ou seja, menos de $50 \%$ do universo de exercícios contidos no capítulo.

Analisamos os 38 exercícios com contexto específico, que nos remeteram a 42 referenciais de sujeitos analisados e apresentados a seguir (tabela 5).

\section{TABELA 5}

ANÁLISE DOS EXERCÍCIOS PROPOSTOS E ATIVIDADES ADICIONAIS EM CONTEXTO ESPECÍFICO

\begin{tabular}{|c|c|c|c|c|c|c|c|c|c|}
\hline$* \mathrm{p}$ & M & $\mathrm{F}$ & 1 & $E$ & 0 & PUXPR & $\mathrm{M}$ & $\mathrm{F}$ & I \\
\hline $337-2$ & João & & & emprestou & dinheiro & $\mathrm{pu}$ & 1 & & \\
\hline $337-3$ & & & $\begin{array}{c}\text { uma } \\
\text { pessoa }\end{array}$ & aplicou & dinheiro & $\mathrm{pu}$ & & & 1 \\
\hline $340-5$ & & & $\begin{array}{c}\text { uma } \\
\text { pessoa }\end{array}$ & aplicou & dinheiro & $\mathrm{pu}$ & & & 1 \\
\hline $340-7$ & $\begin{array}{c}\text { Dois } \\
\text { sócios:Pau } \\
\text { lo e Rafael }\end{array}$ & & & $\begin{array}{c}\text { repartiram } \\
\text { o lucro }\end{array}$ & negócio & $\mathrm{pu}$ & 1 & & \\
\hline $344-15$ & Eu (autor) & & & investi & $\begin{array}{l}\text { fundo de } \\
\text { aplicação }\end{array}$ & $\mathrm{pu}$ & 1 & & \\
\hline $346-21$ & $\begin{array}{c}\text { Um } \\
\text { comerci- } \\
\text { ante }\end{array}$ & & & comprou & peça de tecido & pu & $I$ & & \\
\hline
\end{tabular}




\begin{tabular}{|c|c|c|c|c|c|c|c|c|c|}
\hline $346-23$ & $\begin{array}{l}\text { Luis, } \\
\text { Sérgio }\end{array}$ & Marta & & $\begin{array}{c}\text { recebeu } \\
\text { uma } \\
\text { quantia }\end{array}$ & dinheiro & $x$ & II & 1 & \\
\hline $346-28$ & & & $\begin{array}{c}\text { você } \\
\text { (leitor) }\end{array}$ & comprar & alguma coisa & $x$ & & & 1 \\
\hline $346-29$ & Eu (autor) & & & aumentou & salário & $\mathrm{pu}$ & I & & \\
\hline $346-31$ & Tio João & & & comprou & $\begin{array}{l}\text { lote ações } \\
\text { Petrobrás }\end{array}$ & $\mathrm{pu}$ & I & & \\
\hline $347-36$ & & & $\begin{array}{c}\text { uma } \\
\text { pessoa }\end{array}$ & emprestou & quantia & $\mathrm{pu}$ & & & I \\
\hline $351-46$ & Carlos & & & aplicou & dinheiro & $\mathrm{pu}$ & I & & \\
\hline $351-47$ & Guto & & & aplicar & dinheiro & $\mathrm{pu}$ & I & & \\
\hline $351-48$ & Afonso & & & $\begin{array}{c}\text { depositará } \\
\text { (poup.) }\end{array}$ & dinheiro & $\mathrm{pu}$ & 1 & & \\
\hline $351-49$ & pai & & & investiu & $\begin{array}{l}\text { Fundo de } \\
\text { investimento }\end{array}$ & $\mathrm{pu}$ & I & & * \\
\hline $351-49$ & & Luísa & & $\begin{array}{c}\text { recebeu do } \\
\text { pai }\end{array}$ & dinheiro & $\mathrm{pu}$ & & I & \\
\hline $351-51$ & & & você & investir & capital/quantia & $\mathrm{pu}$ & & & I \\
\hline $351-52$ & & & $\begin{array}{c}\text { uma } \\
\text { pessoa }\end{array}$ & aplicar & valor & $\mathrm{pu}$ & & & I \\
\hline $353-55$ & & & $\begin{array}{l}\text { Torcedo- } \\
\text { res }\end{array}$ & $\begin{array}{l}\text { time de } \\
\text { futebol }\end{array}$ & $\begin{array}{c}\text { no de } \\
\text { torcedores }\end{array}$ & $\mathrm{pu}$ & & & $I^{*}$ \\
\hline $353-56$ & & & $\begin{array}{c}\text { a pop. do } \\
\text { Brasil }\end{array}$ & $x$ & $\begin{array}{l}\text { taxa de } \\
\text { crescimento }\end{array}$ & $\mathrm{pu}$ & & & I \\
\hline $356-61$ & o cliente & & & $\begin{array}{l}\text { recebe } \\
\text { oferta }\end{array}$ & $\begin{array}{l}\text { opção de } \\
\text { pagamento }\end{array}$ & $\mathrm{pu}$ & I & & \\
\hline $356-62$ & & Noemi & & $\begin{array}{l}\text { tem opção } \\
\text { de pgto. }\end{array}$ & um notebook & $\mathrm{pr}$ & & I & \\
\hline $356-63$ & $\begin{array}{c}\text { Um } \\
\text { comprado }\end{array}$ & & & $\begin{array}{c}\text { desembolsa } \\
\text { rá }\end{array}$ & um carro & $\mathrm{pr}$ & 1 & & \\
\hline
\end{tabular}




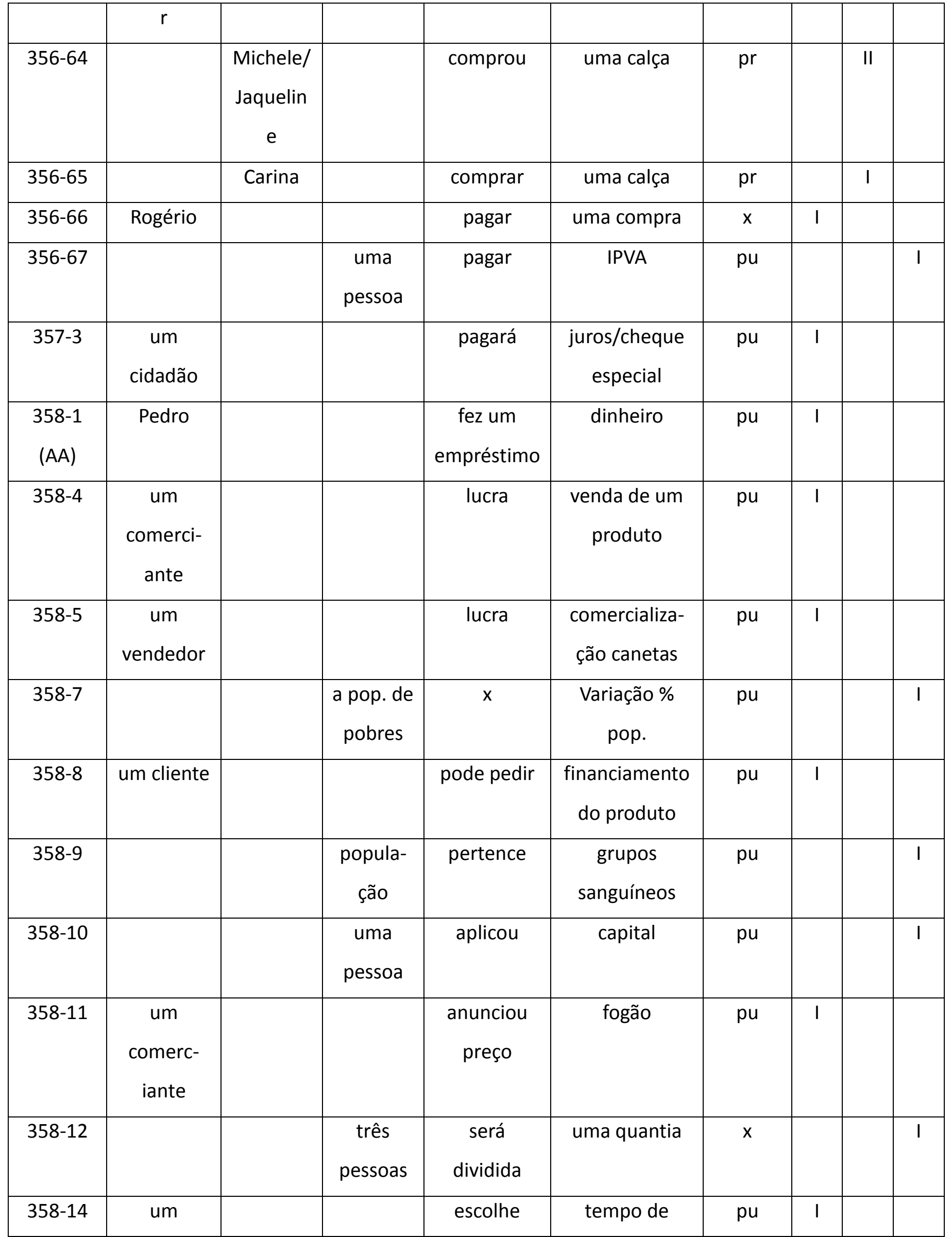




\begin{tabular}{|c|c|c|c|c|c|c|c|}
\hline & motorista & trajeto & viagem & & & & \\
\hline $358-16$ & $\begin{array}{c}\text { um } \\
\text { funcioná- } \\
\text { rio }\end{array}$ & recebeu & indenização & $\mathrm{pu}$ & 1 & & \\
\hline TOTAL & & & & $\begin{array}{l}P U=31 / \\
P R=4\end{array}$ & 23 & 6 & 13 \\
\hline
\end{tabular}

\section{*LEGENDA}

\begin{tabular}{|c|c|c|c|}
\hline $\mathrm{P}$ & página & $\mathrm{E}$ & empoderamento \\
\hline $\mathrm{M}$ & masculino & $\mathrm{O}$ & objeto \\
\hline $\mathrm{F}$ & feminino & $\mathrm{PU}$ X PR & público $\mathrm{x}$ privado \\
\hline $\mathrm{I}$ & Indeterminação de gênero & $\mathrm{T}$ & total \\
\hline $\mathrm{E}$ & empoderamento & $\mathrm{T}$ & total \\
\hline
\end{tabular}

Os resultados demonstram, mais uma vez, o predomínio do gênero masculino, com 23 ocorrências para os referenciais de sujeito presentes nos exercícios. Há a presença de 6 marcadores lexicais para o gênero feminino e 13 para indeterminação do gênero. Tais resultados podem ser visualizados no gráfico de descrição percentual a seguir.

\section{GRÁFICO 3}

\section{REFERENCIAIS DE SUJEITOS EM EXERCÍCOS PROPOSTOS E ATIVIDADES ADICIONAIS}

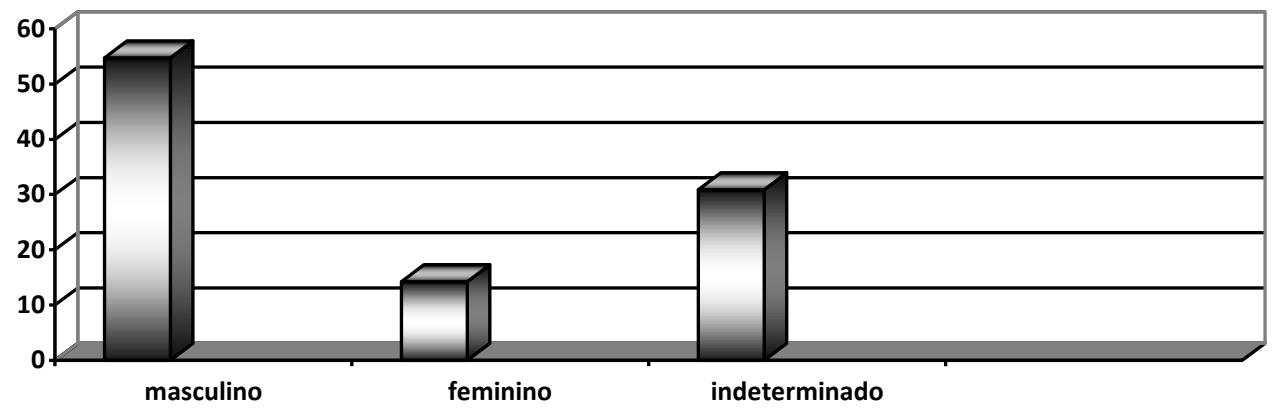

O gráfico nos mostra que $54,7 \%$ dos exercícios analisados apresentam marcadores lexicais para o gênero masculino. Tendo em vista a presença significativa de 30,9\% de recursos garantidores de indeterminação de gênero, verificamos o percentual irrisório de 14,2\% para a presença de 
marcadores lexicais do gênero feminino em tais exercícios. Se já não fosse revelador esse percentual, a análise das relações de empoderamento e dicotomias persistentes do mundo público e privado confirmam mais uma vez as desigualdades nesse universo de $14,2 \%$.

Os 6 enunciados que apresentam marcadores lexicais do gênero feminino podem melhor ser observados no recorte que fizemos e apresentamos na tabela 6 a seguir.

TABELA 6

ANÁLISE DOS MARCADORES LEXICAIS DE GÊNERO FEMININO: EXERCÍCIOS PROPOSTOS E ATIVIDADES ADICIONAIS EM CONTEXTO ESPECÍFICO

\begin{tabular}{|c|c|c|c|c|c|c|c|c|}
\hline$P$ & $\mathrm{M}$ & $F$ & I & $E$ & $\mathrm{O}$ & $\begin{array}{c}\mathrm{Pu} \\
\mathrm{x} \\
\mathrm{pr}\end{array}$ & $M$ & $\mathrm{~F}$ \\
\hline $346-23$ & & Marta & & $\begin{array}{c}\text { recebeu uma } \\
\text { quantia }\end{array}$ & dinheiro & $x$ & & I \\
\hline $351-49$ & & Luísa & & recebeu do pai & dinheiro & $\mathrm{pu}$ & & I \\
\hline $356-62$ & & Noemi & & tem opção de pgto. & $\begin{array}{c}\text { um } \\
\text { noteboo } \\
k\end{array}$ & $\mathrm{pr}$ & & I \\
\hline $356-64$ & & Michele/Jaqueline & & comprou & $\begin{array}{l}\text { uma } \\
\text { calça }\end{array}$ & $\mathrm{pr}$ & & II \\
\hline $356-65$ & & Carina & & comprar & $\begin{array}{l}\text { uma } \\
\text { calça }\end{array}$ & $\mathrm{pr}$ & & 1 \\
\hline TOTAL & & & & & & & & 6 \\
\hline
\end{tabular}

As marcas discursivas nos enunciados desses exercícios confirmam o que já temos visto em outros segmentos analisados: a representação de gênero feminino vinculada a um universo típico do ambiente familiar e privado, conformado a um contexto que silencia as atividades profissionais, as ações envolvendo transações financeiras no âmbito individual e coletivo, atitudes e comportamentos vinculados ao espaço público. Nos 23 enunciados de exercícios propostos e 
atividades adicionais avaliados, também não encontramos qualquer presença de processos discursivos com marca de empoderamento para a representação de gênero feminino.

\subsection{Representações de gêneros no capítulo analisado}

O gráfico 4 nos mostra que, de um universo de 50 fragmentos teóricos, exemplos, exercícios propostos e atividades adicionais apresentados em contexto específico no capítulo, registramos 32 segmentos representados pelo gênero masculino (58\%) e apenas 9 segmentos representados pelo gênero feminino $(16,3 \%)$.

\section{GRÁFICO 4}

DESCRIÇÃO PERCENTUAL DE REFERENCIAIS LEXICAIS DOS GÊNEROS MASCULINO E FEMININO NOS SEGMENTOS ANALISADOS EM CONTEXTO ESPECÍFICO

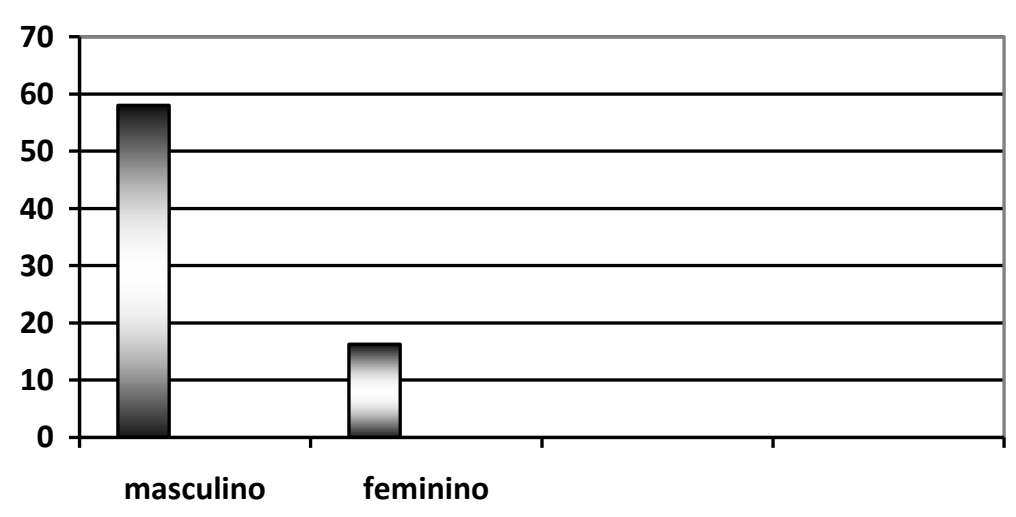

Esse quantitativo torna-se ainda mais desolador quando inserimos esses números no universo mais amplo do total de segmentos apresentados no capítulo, independente de estarem contextualizados (gráfico 5).

\section{GRÁFICO 5}

DESCRIÇÃO PERCENTUAL DE REFERENCIAIS LEXICAIS DOS GÊNEROS MASCULINO E FEMININO EM TODOS OS SEGMENTOS ANALISADOS NO CAPÍTULO 


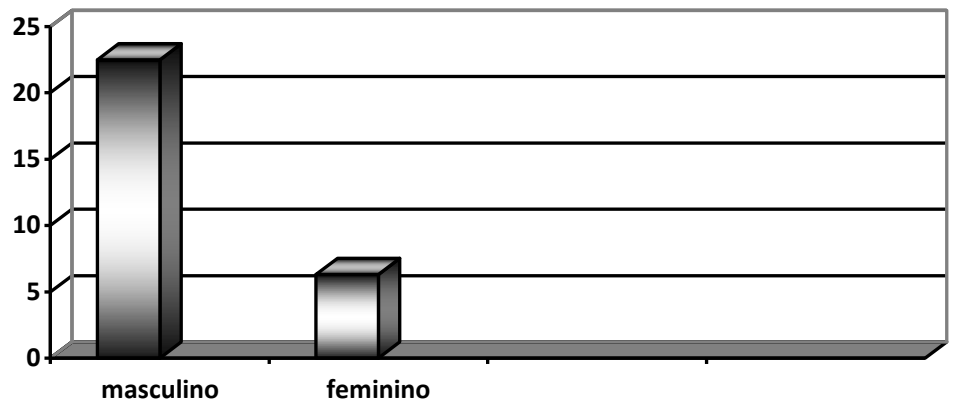

O gráfico mostra que, ao considerarmos os 142 fragmentos teóricos e enunciados de exemplos e exercícios do capítulo analisado, ou seja, em um universo maior que considera o todo do capítulo, os 32 segmentos representados pelo gênero masculino passam a ocupar $22,5 \%$ e os 9 segmentos representados pelo gênero feminino, $6,3 \%$.

Portanto, $71 \%$ dos segmentos do capítulo se encontram em uma das seguintes categorias: estão descontextualizados; apresentam um contexto situacional, desprovido de sujeitos e circunstâncias, o que compromete em muito o processo de aquisição de conhecimento, ou os sujeitos são apresentados com indeterminação de gênero.

\section{CONSIDERAÇÕES FINAIS}

O livro didático ainda exerce um papel fundamental no processo ensino-aprendizagem no Brasil, quer por, muitas vezes, ser o único recurso pedagógico a que estudantes e professores têm acesso, ou por opção metodológica de professores, por variados motivos, nos mais diferentes níveis e modalidades de ensino.

Portanto, é de sobremodo relevante ampliar discussões sobre as análises das representações de gênero presentes no livro didático na medida em que tais representações servem de referencial para estudantes em processo de construção de suas identidades. Nesse sentido, importa refletirmos sobre como este material representa (ou não) identidades sexuais e de gênero em seus enunciados e ilustrações, bem como de que forma a linguagem contribui, de forma pedagógica, para a invisibilidade do gênero feminino. 
Como vimos, os resultados das análises demonstraram que menos de $30 \%$ do conteúdo do capítulo analisado apresenta referenciais de gênero. Esse percentual é bastante significativo porque demonstra o amplo uso (mais de $70 \%$ ) de recursos discursivos que comprometem o processo de construção de conhecimentos de nossos estudantes, quer pela ausência de sujeitos e elementos circunstanciais necessários à essa construção (segmentos descontextualizados), quer por apresentar elementos restritos de especificação, possibilitando transposições mais remotas para situações do cotidiano (segmentos em contexto situacional).

A análise dos segmentos apresentados com referência de gênero masculino e feminino (29\%) demonstrou a presença predominante do gênero masculino, como vimos, com $22,5 \%$ de participação. Os discursos nesses segmentos foram marcados por contextos específicos do mundo público, vinculado a operações comerciais e financeiras, e de comportamentos e ações qualificadoras de empoderamento. A análise da participação feminina (6.3\%) nesses segmentos confirmou os estereótipos vinculados ao papel da mulher no mundo privado e, além de ausência completa de processos discursivos qualificadores de empoderamento, situações de dependência sócio-econômica.

No universo dos segmentos apresentados em contexto específico, cabe destacar o índice de 30\% dos segmentos apresentados com indeterminação de gênero. Tal recurso discursivo, independente das motivações, gera nos enunciados um efeito de ocultação, silenciamento para com a generificação dos sujeitos, uma tentativa infeliz de neutralidade que é massacrada com a presença de todo um contexto de apropriação de estereótipos típicos do universo masculino.

Esse apagamento de construções narrativas impede que estudantes vislumbrem a possibilidade da presença feminina nesses espaços, a possibilidade de construção de valores simbólicos de autoridade, autonomias possíveis, independência em aspectos diversos, em especial, econômicosocial.

Embora possa parecer que estejamos a reiterar o óbvio, na medida em que esse óbvio ainda não venha causando qualquer impacto nas políticas públicas e currículos de nossos estudantes, precisamos, sim, discutir em nossos cursos de formação docente os efeitos dessa "pedagogia de 
invisibilidade" em instrumentos utilizados diariamente por crianças, jovens e adultos no contexto da educação formal.

Precisamos, ainda, dar visibilidade ao fato de que as presenças e ausências verificadas nas análises feitas neste capítulo, observadas nos livros didáticos, nas práticas pedagógicas, no conhecimento corporificado no currículo escolar não devem ser vistas como naturais, como a única forma de se apresentarem (ou não). Elas precisam ser compreendidas como uma opção. Uma opção feita pelo autor, pelos diversos sujeitos da comunidade escolar, de nossos cursos de licenciatura e das políticas educacionais em nosso país. Uma opção constituída pelo conjunto de tradições, valores, pertencimentos que chegam até nós em processos consensuais, como se fossem uma única verdade. Embora saibamos que, por isso mesmo, somos, a princípio, reprodutores destes processos, é possível romper esse caminho. É possível investigarmos, questionarmos nossas práticas, investindo no que eu denominaria de micropolítica de visibilidade daquelas e daqueles que estão ocultos e silenciados por consensos em busca de pura hegemonia.

\section{REFERÊNCIAS}

DANTE, Luiz Roberto. Matemática: contexto e aplicações. São Paulo: Ed. Ática, 2011.

DUCROT, Oswald. Pressupostos e subentendidos (reexame). In: 0 dizer e o dito. Campinas: Ed. Pontes, 1987.

GOHN, Maria da Glória. Empoderamento e participação da comunidade em políticas sociais. In: Saúde e Sociedade. São Paulo, v.13, n.2, p.20-31, maio-ago 2004.

GEERTZ, C. O saber local: novos ensaios em antropologia interpretativa. Petrópolis: Vozes, 1997.

KLEBA, Maria Elisabeth; WENDAUSEN, Agueda. Empoderamento: processo de fortalecimento dos sujeitos nos espaços de participação social e democratização política. In: Saúde e Sociedade. São Paulo, v.18, n.4, p.733-743, 2009.

LEAL, Edilene M. de Carvalho. Jacques Derrida: pensador da desconstrução pensador da diferença. In: Anais do XV Encontro Nacional da Associação Brasileira de Psicologia Social. Maceió, 2009.

LEITE, Fernanda Capibaribe. Na Trilha dos Sujeitos: audiovisual, memória e o evento de empoderamento para as mulheres. In: Revista GEMInIS. UFSCAR-SP, ano 3, n. 2, p. 206-222, 2012.

MCLAREN, Peter. Multiculturalismo crítico. SP: Ed. Cortez, 1997.

LOURO, Guacira Lopes. Pedagogias da sexualidade. In: LOURO, Guacira L. (org). O corpo educado: pedagogias da sexualidade. 2.ed. Belo Horizonte, 2001. 
Gênero, sexualidade e educação: uma perspectiva pós-estruturalista.

13a ed. Petrópolis, RJ: Ed. Vozes, 2011.

OLIVEIRA, Nilceia Bueno de. A perspectiva teórica de Homi K. Bhabha: um caminho possível para a formação continuada de professores de língua estrangeira. Revista X, UFP-PR: v. 1, p. 112-125, 2012.

SANCHIS, Isabelle de Paiva; MAHFOUD, Miguel. Interação e construção: o sujeito e o conhecimento no construtivismo de Piaget. In: Ciências e Cognição. V. 12, p. 165-177, 2007. Disponível em: http://www.cienciasecognicao.org.

SANTOS, Kátia Costa dos. Construção multicultural: reflexões sobre políticas alternativas para o ensino de língua estrangeira. Tese de doutorado: Universidade de São Paulo-USP, SP, 2002.

Disponível em http://teses.usp.br/teses/disponiveis/8/8147/tde-28042003-160345/

SCOTT, Joan W. Gênero: uma categoria útil de análise histórica. Educação \& Realidade. Porto Alegre, v. 20, n. 2, p. 71-99, jul./dez. 1995.

SILVA, Tomaz Tadeu da. Documentos de identidade: uma introdução às teorias do currículo. Belo Horizonte: Ed. Autêntica, 1999.

TRAVAGLIA, Luiz Carlos. Um estudo textual-discursivo do verbo no português do Brasil. Tese de doutorado: Universidade Estadual de Campinas, SP, 1991. 